\title{
MISTERY BOX SEBAGAI MEDIA PEMBELAJARAN UNTUK MENINGKATKAN KEMAMPUAN KOGNITIF KOMPETENSI SIKLUS AKUNTANSI PERUSAHAAN DAGANG
}

\author{
DIAH ARUMSASI \\ SMA Negeri 2 Mranggen \\ e-mail : diaharumsasi3@gmail.com
}

\begin{abstract}
ABSTRAK
Pembelajaran konvensional cenderung berpusat pada guru menjadikan pembelajaran monoton dan membosankan, siswa tidak aktif dan malas sehingga pemahaman siswa menjadi rendah. Pemakaian Media yang tepat mampu menjadi stimulus bagi siswa untuk lebih antusias dalam mengikuti proses belajar mengajar. Hal ini memerlukan ide kreatif dari guru sebagai perancang dan pelaksana skenario pembelajaran di kelas.Tujuan penelitian ini adalah Mengetahui apakah Model Pembelajaran Problem Base Learning dapat meningkatkan pemahaman dan penguasaan siswa mengenai konsep Siklus Akuntansi Perusahaan dagang. Dalam Best Practise ini juga menggunakan bahan daur ulang berupa Kardus yang dibentuk sebagai media bernama "Mistery Box" untuk memberikan ilustrasi dan simulasi kepada siswa mengenai materi perusahaan dagang. "Mistery Box" yang dilakukan pada proses pembelajaran sekaligus program Lesson Study yang dilaksanakan bersama dengan observasi dan pendampingan Tim Kurikulum 2013 dari LPMP Propinsi Jawa Tengah dan pengawas SMA Kabupaten Demak di SMA Negeri 2 Mranggen Kelas XII IPS 5 pada materi Siklus Akuntansi Perusahaan Dagang pada tahun 2018 diharapkan mampu memberi dampak positif dalam proses belajar mengajar sekaligus sebagai sekolah dan guru model Implementasi Kurikulum 2013.
\end{abstract}

Kata kunci : Pemahaman Konsep, Problem Based Learning, Cooperative Learning, Role Playing, Video Pembelajaran, Mistery Box, Media Pembelajaran.

\begin{abstract}
Conventional learning tends to be teacher-centered, making learning monotonous and boring, students are not active and lazy so that student understanding becomes low. The use of the right media can be a stimulus for students to be more enthusiastic in participating in the teaching and learning process. This requires creative ideas from the teacher as a designer and implementer of learning scenarios in the classroom. The purpose of this study is to find out whether the Problem Base Learning Model can improve students' understanding and mastery of the concept of the Trading Company Accounting Cycle. This Best Practice also uses recycled materials in the form of cardboard which is formed as a medium called "Mystery Box" to provide illustrations and simulations to students regarding trading company materials. The "Mystery Box" was carried out in the learning process as well as the Lesson Study program which was carried out together with the observation and assistance of the 2013 Curriculum Team from the LPMP Central Java Province and the Demak Regency Senior High School supervisor at SMA Negeri 2 Mranggen Class XII IPS 5 on the material of the Accounting Cycle of Trading Companies in 2018 is expected to have a positive impact on the teaching and learning process as well as schools and teachers of the 2013 Curriculum Implementation model.
\end{abstract}

Keywords: Concept Understanding, Problem Based Learning, Cooperative Learning, Role Playing, Learning Videos, Mystery Box, Learning Media.

\section{PENDAHULUAN}

Dalam proses kegiatan belajar rmengajar di kelas ditemukan beberapa kesulitan belajar yang mencerminkan tingkat kemampuan siswa. Kesulitan belajar dapat ditunjukkan dari respon siswa terhadap materi yang disampaikan guru. Kesulitan belajar juga terlihat dari hasil belajar atau prestasi yang diperoleh siswa. 
Prestasi belajar merupakan tolok ukur maksimal yang telah dicapai siswa setelah melakukan proses belajar selama waktu yang ditentukan. Prestasi belajar siswa banyak dipengaruhi oleh berbagai faktor, baik berasal dari dalam dirinya (internal) maupun dari luar dirinya (eksternal).

Prestasi belajar menurut Depdiknas (2007) merupakan hasil yang telah dicapai (dilakukan, dikerjakan, dan sebagainya). Nana (2005) yang mendefinisikan prestasi adalah hasil belajar yang dicapai siswa dengan kriteria tertentu. Sehingga untuk mengetahui tingkat prestasi belajar maka perlu dilakukan evaluasi belajar. Penilaian dilaksanakan dengan evaluasi pada PBM sehingga akan diketahui nilai dari prestasi belajar siswa. Berdasarkan uraian di atas dapat disimpulkan bahwa prestasi belajar adalah hasil yang telah dicapai seorang siswa yang dinyatakan dalam bentuk nilai, baik huruf maupun angka yang mencerminkan penguasaan pengetahuan dan keterampilan tentang materi pelajaran yang telah disampaikan.

Dengan mengkaji hal tersebut di atas, maka faktor-faktor yang dapat memengaruhi prestasi belajar menurut Purwanto (1990) adalah: (1) faktor yang ada pada diri organisme itu sendiri yang dapat disebut faktor individual, seperti kematangan/pertumbuhan, kecerdasan, latihan, motivasi, dan faktor pribadi, (2) faktor yang ada di luar individu yang disebut faktor sosial, seperti faktor keluarga/ keadaan rumah tangga, guru dan cara mengajarnya, alat-alat yang dipergunakan dalam belajar-mengajar, lingkungan dan kesempatan yang tersedia, dan motivasi sosial. Slameto (2010) menyatakan bahwa faktor-faktor yang memengaruhi belajar banyak jenisnya, tetapi dapat digolongkan menjadi dua golongan yaitu faktor intern dan faktor ekstern.

Setiap individu pasti mempunyai kebutuhan, dalam mencukupi kebutuhan hidupnya pastilah individu mempertimbangkan secara rasional mengenai cara menggunakan sumber daya atau pendapatan tertentu agar penggunaa tersebut dapat memberikan kepuasan dan kemakmuran yang maksimum kepada individu dan masayarakat. Dalam mempelajari itu semua diperlukan analisis-analisis ekonomi yang dibedakan menjadi tiga golongan, yaitu: ilmu ekonomi deskriptif, teori ekonomi, dan ilmu ekonomi terapan. Dalam pemenuhan barang kebutuhan tersebut ada peran Perusahaan Dagang.

Kompetensi Dasar di semester 1 pada kelas XII ini dipelajari Materi Siklus Akuntansi Perusahaan Dagang. Materi ini penting dipelajari oleh siswa karena perusahaan dagang merupakan roda penggerak dalam menawarkan dan menciptakan produk yang diperdagangkan untuk memenuhi kebutuhan manusia.

Hampir setiap kegiatan perekonomian masyarakat tidak terlepas dari peran perusahaan dagang. Dalam menjalankan aktifitasnya, perusahaan dagang menawarkan berbagai produk yang berisi kegiatan pendukung perekonomian masyarakat, mulai dari membeli dan menjual barang baik secara tradisional ataupun modern (online) intinya mempermudah masyarakat melakukan aktifitas bisnis dan perekonomian sehari-hari. Sebagian masyarakat sendiri secara tidak sadar telah merasa tergantungdengan kegiatan perusahaan dagang tersebut untuk melakukan aktifitas perekonomiannya, mulai dari berbelanja sehari-hari sampai sekedar untuk pengisian pulsa bagi telepon selularnya. Hal ini bukan hanya sekedar trend dalam masyarakat, tetapi memang perkembangan jaman dan teknologi serta perkembangan kebutuhan masyarakat sehingga menuntun peran besar perusahaan dagangan dalam sendi-sendi kehidupan perekonomian pada saat ini. Adapun Tujuan penelitian ini adalah (1) Mengetahui apakah Model Pembelajaran Problem Base Learning dapat meningkatkan pemahaman dan penguasaan siswa mengenai konsep Siklus Akuntansi Perusahaan dagang

Selanjutnya Winkel (1991) menyatakan bahwa prestasi belajar dapat dilihat dengan memantau prestasai akademik siswa. Prestasi akademik biasanya diukur dari nilai sehari-hari hasil tes belajar dan lamanya bersekolah. Skor prestasi belajar merupakan hasil yang dicapai mahasiswa pada mata pelajaran tertentu yang diwujudkan dalam bentuk angka.

Peran guru diperlukan untuk meningkatkan prestasi siswa melalui cara mengajar yang lebih bervariasi serta bisa meningkatkan motivasi. Guru hendaknya memperhatikan pendekatan 
pembelajaran, metode pembelajaran, model pembelajaran, strategi pembelajaran dan teknikteknik dalam pembelajaran

Pendekatan Pembelajaran dapat diartikan sebagai titik tolak atau sudut pandang kita terhadap proses pembelajaran, yang merujuk pada pandangan tentang terjadinya suatu proses yang sifatnya masih sangat umum, di dalamnya mewadahi, menginsiprasi, menguatkan, dan melatari metode pembelajaran dengan cakupan teoretis tertentu. Dilihat dari pendekatannya, pembelajaran terdapat dua jenis pendekatan, yaitu: (1) pendekatan pembelajaran yang berorientasi atau berpusat pada siswa (student centered approach) dan (2) pendekatan pembelajaran yang berorientasi atau berpusat pada guru (teacher centered approach).

Metode pembelajaran dapat diartikan sebagai cara yang digunakan untuk mengimplementasikan rencana yang sudah disusun dalam bentuk kegiatan nyata dan praktis untuk mencapai tujuan pembelajaran. Menurut Sudjana (2005) metode pembelajaran adalah, "Metode pembelajaran ialah cara yang dipergunakan guru dalam mengadakan hubungan dengan siswa pada saat berlangsungnya pengajaran". Model pembelajaran diartikan sebagai prosedur sistematis dalam mengorganisasikan pengalaman belajar untuk mencapai tujuan belajar. Dapat juga diartikan suatu pendekatan yang digunakan dalam kegiatan pembelajaran.

Jadi, sebenarnya model pembelajaran memiliki arti yang sama dengan pendekatan, strategi atau metode pembelajaran. Saat ini telah banyak dikembangkan berbagai macam model pembelajaran, dari yang sederhana sampai model yang agak kompleks dan rumit karena memerlukan banyak alat bantu dalam penerapannya.

Menurut E. Mulyasa (2003) mengetengahkan lima model pembelajaran yang dianggap sesuai dengan tuntutan Kurikukum Berbasis Kompetensi; yaitu : (1) Pembelajaran Kontekstual (Contextual Teaching Learning); (2) Bermain Peran (Role Playing); (3) Pembelajaran Partisipatif (Participative Teaching and Learning); (4) Belajar Tuntas (Mastery Learning); dan (5) Pembelajaran dengan Modul (Modular Instruction). Model pembelajaran diterapkan disesuaikan dengan keadaan siswa. Penerapan model pembelajaran yang tepat akan membawa hasil yang lebih maksimal terhadap peningkatan hasil belajar atau prestasi siswa.

Banyak model pembelajaran yang bisa digunakan oleh guru. Salah satunya adalah problem base learning. Model pembelajaran berbasis masalah merupakan sebuah model pembelajaran yang menyajikan masalah kontekstual sehingga merangsang peserta didik untuk belajar. Dalam kelas yang menerapkan pembelajaran berbasis masalah, peserta didik bekerja dalam tim untuk memecahkan masalah dunia nyata (real world). PBL (problem base learning) dapat meningkatkan kemampuan berpikir kritis, menumbuhkan inisiatif peserta didik/mahapeserta didik dalam bekerja, motivasi internal untuk belajar, dan dapat mengembangkan hubungan interpersonal dalam bekerja kelompok.

Belum ada yang mengungkapkan pendapat mengenai Mistery Box karena ini masih murni ide dari saya sebagai guru yang muncul untuk menstimulus siswa dalam belajar mengenai perusahaan dagang. Mistery Box ini adalah alat yang merupakan ide dari barang kardus ( bekas) yang digunakan dalam pembelajaran. Hanya sederhana berisi benda-benda bekas dan katalog ataupun yang terkait dengan barang dagangan di perusahaan dagang yang menunjukkan sebuah aktivitas dan karakteristik perusahaan dagang.

\section{METODE PELAKSANAAN}

Dalam Best Practise ini juga menggunakan sebuah media berbasis IT berupa kompilasi video dari Perusahaan dagang sehingga diharapkan siswa mampu melihat lebih dekat mengenai jenis perusahaan dagang ini. Dengan menggunakan video inipun diharapkan pembelajaran menjadi lebih efektif dan menyenangkan.

Dalam Best Practise ini juga menggunakan leaf leat dari produk perusahaan dagang yang merupakan tugas mandiri berkelompok dari siswa untuk selanjutnya bisa diterapkan sebagai kombinasi dari model pembelajaran Problem Base Learning, Cooperative Learning dan Role Playing. Karena siswa diharapkan mampu menemukan masalah dan 
mengkomunikasikan dalam kelas mengenai produk-produk perusahaan dagang yang ada di sekitar lingkungan mereka.

Dalam Best Practise ini juga menggunakan bahan daur ulang berupa Kardus yang dibentuk sebagai media bernama "Mistery Box" untuk memberikan ilustrasi dan simulasi kepada siswa mengenai materi perusahaan dagang.

Pembelajaran kooperatif adalah salah satu bentuk pembelajaran yang berdasarkan faham konstruktivis. Pembelajaran kooperatif merupakan strategi belajar dengan sejumlah siswa sebagai anggota kelompok kecil yang tingkat kemampuannya berbeda. Dalam menyelesaikan tugas kelompoknya, setiap siswa anggota kelompok harus saling bekerja sama dan saling membantu untuk memahami materi pelajaran. Dalam pembelajaran kooperatif, belajar dikatakan belum selesai jika salah satu teman dalam kelompok belum menguasai bahan pelajaran.

\section{HASIL DAN PEMBAHASAN}

\section{A. Alasan Strategi Pemecahan Masalah yang dipilih}

Alasan pemilihan kompetensi dasar ini adalah akuntansi adalah hal yang baru yang diperoleh di kelas XII. Dengan mempelajari secara teori saja menyebabkan peserta didik sulit memperoleh gambaran yang jelas mengenai akuntansi dan perusahaan dagang itu sendiri. Pola pembelajaran tradisional akan membuat peserta didik menjadi bosan dan kurang antusias dalam mengikuti proses pembelajaran.

Best Practise ini ditulis berdasarkan pengalaman mengajar yang diterapkan di SMA Negeri 2 Mranggen Kabupaten Demak kelas XII IPS.

\section{Tahapan Operasional Pelaksanaan Pemecahan Masalah}

Hal yang dilakukan dalam pembelajaran ini adalah :

\section{a. Perencanaan}

1. Menganalisis/ Memilih materi pelajaran

2. Membuat rencana pembelajaran

3. Melaksanakan proses pembelajaran secara ceramah

b. Pelaksanaan

Pada tahapan ini meliputi dua pertemuan, pertemuan pertama dilaksanakan penyusunan dan cooperative learning/ diskusi kelompok dilanjutkan mempresentasikan di kelas pada materi Perusahaan dagang.

\section{c. Observasi}

Obeservasi dilakukan oleh observer (pengamat) untuk mengamati aktifitas siswa dalam melakukan kegiatan presentasi kelompok dan menilai aktivitas yang dilakukan tiap kelompok. Dalam pelaksanaan pembelajaran yang di tulis dalam Best Practise ini di amati pula oleh pengamat Pendamping Kurikulum 2013 dari LPMP, Pengawas Sekolah, Kepala Sekolah, dan Observer (guru pengamat).

\section{d. Refleksi}

Pada tahapan ini dilakukan analisis hasil observasi dalam hal ini penilai sebagai bentuk refleksi dan evaluasi pelaksanaan kegiatan belajar mengajar dan evaluasi kepada guru observer.

\section{B. Hasil/ Dampak Yang Dicapai Dari Strategi Yang Dipilih}

Strategi dan penerapan model pembelajaran ini memberikan dampak/ hasil sebagai berikut : Sebelum menggunakan model pembelajaran ini ;

- Siswa kurang antusias dan bersemangat untuk mempelajari pelajaran yang cukup rumit

- Siswa tidak mau membaca/ kurang minat baca

- Siswa belum mampu maksimal bekerja sama dalam kelompok untuk menyelesaikan masalah. 


\section{Setelah menggunakan model pembelajaran inin :}

- Siswa cukup antusias dan bersemangat untuk mempelajari pelajaran yang cukup rumit

- Siswa mau membaca/ kurang minat baca

- Siswa mampu maksimal bekerja sama dalam kelompok untuk menyelesaikan masalah.

\section{Kendala yang dihadapi :}

- Butuh waktu yang cukup lama untuk mempersiapkan

- Butuh kesabaran untuk mensosialisaikan kepada siswa aturan main/ role playing

- Diperlukan motivasi lebih untuk para siswa dalam belajar menggunakan model pembelajaran ini.

\section{Faktor pendukung :}

- Dukungan sekolah

Dukungan yang diberikan sekolah berupa fasilitas IT berupa $L C D$ dan speaker, serta ruang yang representatif untuk siswa nyaman belajar meskipun ditunggu oleh para observer yang melakukan lesson study.

- Observasi dan kolaborasi dari berbagai pihak

- Bahan media cukup mudah diperoleh

- Sarana dan prasarana dalam kegiatan belajar ini cukup memadai.

\section{Alternatif penerapan :}

- Model pembelajaran ini bisa diterapkan untuk kompetensi dasar lainnya.

- Kepala sekolah juga harus senantiasa memberi motivasi terhadap guru untuk selalu mengembangkan diri dan proaktif mencari informasi/ sumber untuk mendukung pengembangan diri, sekolah dan siswa.

\section{KESIMPULAN}

Pembelajaran dengan model pembelajaran ini mampu memberikan warna baru dan inovasi baru dalam pendidikan dan dampak / hasil dari model pembelajaran ini cukup memuaskan. Berdasarkan pembahasan di atas, maka diharapkan guru lebih mengembangkan diri dan berani menerapkan model-model pembelajaran yang bervariasi dalam rangka meningkatkan hasil belajar siswa.

\section{Rekomendasi :}

Berdasarkan pencapaian hasil belajar dan pengamatan yang dilaksanakan maka direkomendasikan :

- Perlu kerjasama yang baik dan evaluasi yang berkesinambungan dalam penerapan kurikulum 2013

- Perlu lesson study antar guru satu rumpun mata pelajaran bahkan beda mata pelajaran untuk memberikan ide positif dalam memberi inovasi pada proses belajar mengajar yang dilakukan di kelas.

- Pembelajaran dengan problem base learning dapat dilakukan materi-materi yang sulit dikuasai siswa (abstrak)

- Pembelajaran dengan problem based learning membutuhkan sarana pendukung yang memadai seperti buku acuan, internet dan fasilitas IT.

\section{DAFTAR PUSTAKA}

Arikunto S., Suhardjono., Supardi. 2006. Penelitian Tindakan Kelas. Jakarta. Bumi Aksara

Hamdan, Dessy. (2016). Pemanfaatan Video sebagai Media Pembelajaran Matematika SD/MI. Muallimuna: Jurnal Madrasah Ibtidaiyah, Vol 2 No 1

Permendikbud No 65 Tahun 2013, Standart Proses. Jakarta

Purwanto. 2013. Pengaruh Kemampuan Bersosialisasi, Kemandirian Belajar dan Kemampuan

Beradaptasi Terhadap Prestasi Belajar Pada Mata Pelajaran Elektronika Industri

Terapan Siswa Kelas XI SMK Negeri 2 Pengasih”. Universitas Negeri Yogyakarta.

Slameto. 2002. Belajar \& Faktor - Faktor yang mempengaruhinya. Bandung : Rineka Cipta 
Sugiyono. 2013. Metode Penelitian Pendidikan, Pendekatan Kuantitatif, Kualitatif dan R\&D. Bandung. Alfabeta.

Sumadi Suryabrata. 2004. Psikologi Pendidikan. Jakarta: Raja Grasindo Persada.

Syaiful Bahri Djamarah. 2011. Psikologi Belajar. Rineka Cipta: Jakarta 